\title{
THE OXYTOCIN RELEASE AND THE COMPOUND ACTION POTENTIAL EVOKED BY ELECTRICAL STIMULATION ON THE ISOLATED NEUROHYPOPHYSIS OF THE RAT
}

\author{
Ayako ISHIDA \\ Department of Physiology, School of Medicine, \\ Juntendo University, Hongo, Tokyo, Japan
}

Since it has been demonstrated that the electrical membrane properties of the hypothalamic neuroendocrine cells of the goldfish (KANDEL, 1964), and the neurosecretory cells in the X-organ-sinus gland complex of the crayfish (IWASAKI, 1968), are quite similar to those of nerve cells, the proposed idea that these cells play the dual roles of impulse conduction and hormone secretion has been firmly confirmed. It has also been suggested that the secretory activity in the neurohypophysis of higher vertebrate is regulated by impulses of the hypothalamo-hypophysial tract coming down through the pituitary stalk to the neurohypophysis (DE RoBERTIS, 1964; BROOKS and Korzumi, 1964 ; Douglas, 1966). Recently it was observed that an electrical field stimulation to the isolated neurohypophysis is effective for the release of vasopressin (MIKITEN, 1965; HAller et al., 1965). Moreover, IsHikAWA et al. (1966) showed that the nerve impulses could be observed at the pituitary stalk of the cat on suction of the mammary gland or the distention of the uterus. However, the real correspondence of the release of hormone in the neurohypophysis to the electrical activity of the hypothalamo-hypophysial tract still remains obscure.

The present paper is focused on examining the relation between the action potentials through the pituitary stalk and the amount of oxytocin released from the neurohypophysis of the rat on the application of electrical stimulation to the stalk.

\section{METHODS}

Preparation: Material used was the isolated pituitary gland of the male rat, weighing 200-300 g, with a small piece of the stalk. The gland was taken out, paying special attention to avoid injury, after decapitation with a guillotine. It was left for

Received for publication July 16, 1969

石田絢子 
10-20 min in a partition box which was filled with Locke solution, bubbled with $95 \%$ $\mathrm{O}_{2}$ and $5 \% \quad \mathrm{CO}_{2}$ gas mixture, and kept at $36-37^{\circ} \mathrm{C}$ in order to diminish the effect of injury accompanied by the isolation.

Solution: The modified Locke solution with the following composition $(\mathrm{mM})$ was used, $\mathrm{NaCl}, 154 ; \mathrm{KCl}, 5.6 ; \mathrm{NaHCO}_{3}, 6.0 ; \mathrm{CaCl}_{2}, 2.2 ; \mathrm{MgCl}_{2}, 1.0 ;$ glucose, 10.0 . Excess K-Locke solution, in which $\mathrm{NaCl}$ of $56.0 \mathrm{mM}$ was replaced by isomolar $\mathrm{KCl}$, and $\mathrm{Na}$ defficient Locke solution in which $\mathrm{NaCl}$ of $154 \mathrm{mM}$ was replaced by isomolar cholinchloride, were also used.

Electrical stimulation and potential recording: The isolated gland was mounted in a partition box (FIG. 1) which had two chambers $\left(\mathrm{C}_{1}\right.$ and $\mathrm{C}_{2}$ ) separated by a partition wall $(\mathrm{W})$ at the center so as to make the stalk come through the partition wall. A bit of high vacuum grease (V) was inserted into the gap between the stalk and the partition wall to make the insulation at the partition complete. A pair of platinum plates $\left(S_{1}\right.$ and $\left.S_{2}\right)$, soaked in the solution on the both sides of the partition wall, were connected to a stimulator (MSE 3, Nihon Kohden). A square pulse with the duration

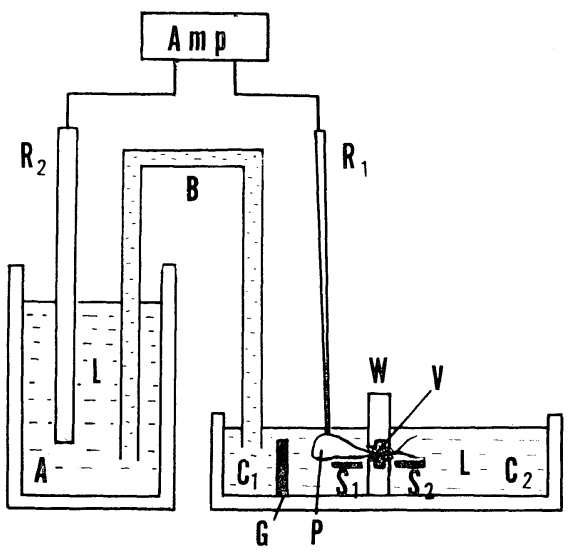

FIG. 1. A diagram of the experimental arrangement. $\mathrm{C}_{1}$ and $\mathrm{C}_{2}$ are two chambers divided by dropped acryl plate $(W)$ which is $0.67 \mathrm{~mm}$ thick. $P$ : pituitary gland, $V$ : high vacuum grease, $S_{1}$ and $S_{2}$ : two platinum plates in each division for the stimulating electrode, $G$ : platinum plate for the ground, $\mathrm{R}_{1}: \mathrm{Ag}-\mathrm{AgCl}$ microelectrode for the recording, $\mathrm{R}_{2}: \mathrm{Ag}-\mathrm{AgCl}$ wire for the indifferent electrode placed in another chamber (A) which connected to the chamber $\mathrm{C}_{1}$ with the agar-Locke bridge (B). Each chamber was filled with Locke solution (L).

of $0.02 \mathrm{msec}$ was given through an isolator to prevent stimulus artifact and the current intensity was less than $1 \mathrm{~mA}$. Sometimes, a stronger stimulus of more than $1 \mathrm{~mA}$, without using the isolator, was necessary to obtain a sufficient amount of oxytocin release. One $\mathrm{Ag}-\mathrm{AgCl}$ wire microelectrode $\left(\mathrm{R}_{1}\right.$ : tip diameter was $\left.50-100 \mu\right)$ was placed on the gland as a recording electrode under the control of the micromanipulator and connected to the amplifier. Another $\mathrm{Ag}-\mathrm{AgCl}$ electrode $\left(\mathrm{R}_{2}\right)$ was placed in the indifferent bath (A) connected to the chamber $\mathrm{C}_{1}$ with agar Locke bridge (B) to keep it at a sufficient distance from the chamber $\mathrm{C}_{1}$. Thus the action potential was recorded monophasically. A platinum ground plate $(G)$ was put into the chamber $C_{1}$ in order to minimize the stimulus artifact. 
Measurement of the hormone: The oxytocin content released into the solution in the chamber $\mathrm{C}_{1}$ was measured by bio-assay using guinea-pig of postpartum 4-7 days as described in a previous paper (ISHIDA, 1968), and the vasopressin content was assayed by its pressor effect on the rat as described in another previous paper (IsHIDA, 1967). Before stimulation the gland was left for $10 \mathrm{~min}$ without stimulation and the oxytocin content of the external medium in the resting state was measured as a control. Then about $0.6-0.8 \mathrm{ml}$ of new Locke solution was put in the chamber $\mathrm{C}_{1}$, and the stalk was stimulated for $5 \mathrm{~min}$ by repetitive pulses. After $2 \mathrm{~min}$ from the cessation of the stimulus the solution was collected and assayed. The intensity of stimulation was usually raised so as to increase the oxytocin release more than twice of the control value.

\section{RESULTS}

\section{Compound action potential evoked by the electrical stimulation at the stalk}

1) Typical compound action potential. When the distance between the stimulating and recording electrodes was $1.75 \mathrm{~mm}$, two peaks were obtained in the action potential evoked by the supramaximal single shock, as shown in FIG. 2A. The mean value of the time to the first peak from stimulus was $1.5 \pm 0.3 \mathrm{msec}(\mathrm{n}=7)$ and to the second peak was $3.6 \pm 0.5 \mathrm{msec}(\mathrm{n}=10)$. In another experiment, two recording electrodes were attached to the gland, the proximal and distal ones being placed at a distance of $1.02 \mathrm{~mm}$ and $1.67 \mathrm{~mm}$ from the stimulated site respectively. The simultaneous records of action potentials obtained from two electrodes were shown in FIG. 2B. It is clear that only one peak is observed in the proximal record but two peaks are seen in the distal record. The records which were taken from the results of stimulation with three different intensities were shown in FIG. 2C. When the stimulus intensity was weak, the potential curve was not separated into two waves in both proximal and distal records. But it separated into two waves when the stimulus intensity was increased. The complete separation into two waves was obtained in the distal record taken with a stimulation of a strong intensity (FIG. 2C, marked d on top). It was difficult to obtain the complete wave separation, when i) the distance between stimulating and recording electrodes was too close, ii) the stimulus intensity was too weak, or iii) the excitability of the preparation was not sufficiently high.

As the external $\mathrm{K}^{+}$concentration has some influences on the compound action potential as it does on the non-myelinated nerve fiber, effect of changing $\mathrm{K}^{+}$concentration in Locke solution was examined. The potential in normal Locke solution is shown in FIG. 3A-1, then the gland was soaked in the 56.0 $\mathrm{mM} \mathrm{K}^{+}$Locke solution. The amplitude of the action potential was potentiated after $30 \mathrm{sec}$ soaking, in some cases, to $130 \%$ of the control, but after 1-2 min it markedly decreased (FIG. 3A-2,3), and disappeared finally about 5 min later. When the external $\mathrm{Na}^{+}$was replaced by choline, the action potential almost disappeared within $10 \mathrm{~min}$ (FIG, 3B-2), These effects of excess $\mathrm{K}^{+}$or 


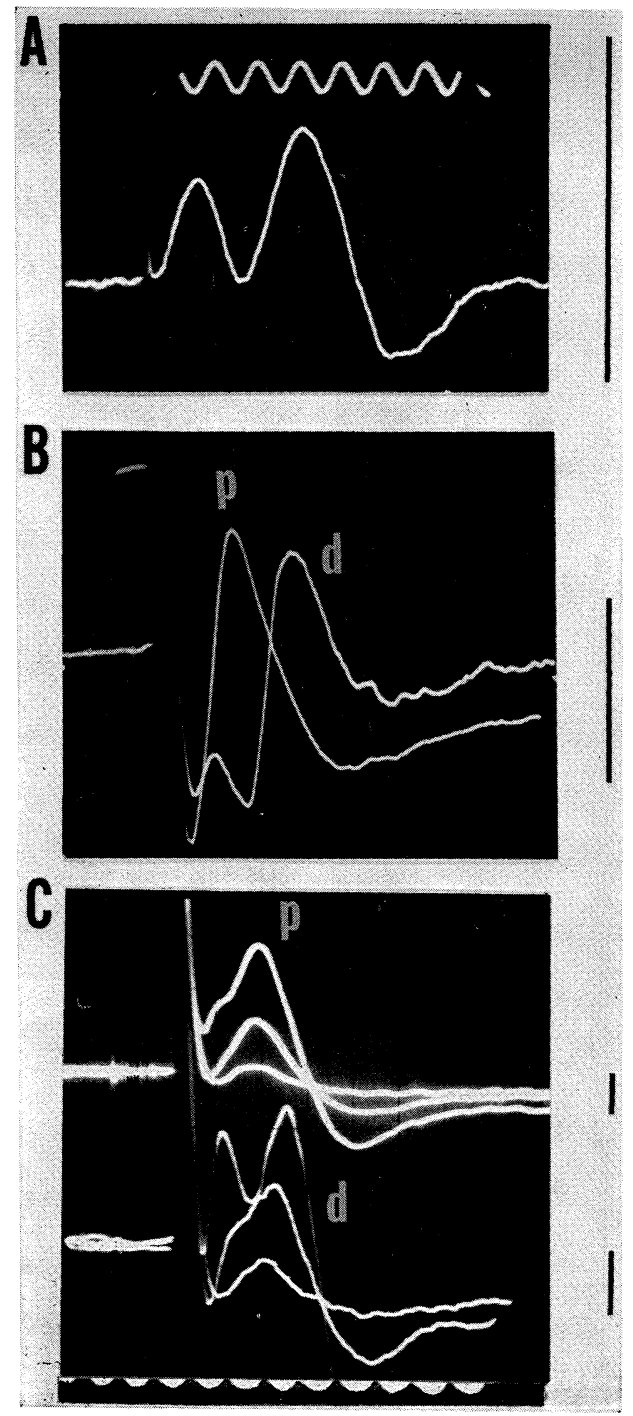

FIG. 2. Typical compound action potential elicited by a single shock stimulation. A: The potentials were recorded at $1.75 \mathrm{~mm}$ distance from the starting point of the conduction. B: Simultaneous recording from the two sites, p: proximal site at $1.02 \mathrm{~mm}$ distance and $\mathrm{d}$ : distal site, $1.67 \mathrm{~mm}$. C: Three pairs of records which indicated the change of the potential pattern caused by increasing the intensity of stimulus from the bottom to the top, $\mathrm{p}: 1.59 \mathrm{~mm}$, and $\mathrm{d}: 2.00$ $\mathrm{mm}$. Time marks in each figure equal $1 \mathrm{msec}$ and each vertical bars (calibration) indicate $100 \mu \mathrm{v}$.

$\mathrm{Na}^{+}$deficiency on the action potential were restored within $5 \mathrm{~min}$, if the solution was replaced with Locke solution.

2) Calculation of conduction velocity. Two recording electrodes were placed on the gland. The conduction velocity was calculated by dividing the conduction distance by the difference of conduction time measured on the simultaneous recording using these electrodes. These results can be seen in TABLE 1, No. 3, 4 and 5. Another method was also used to estimate the conduction velocity. The stimulating point was varied under the same recording electrode. In order to vary the location of stimulating point, the 

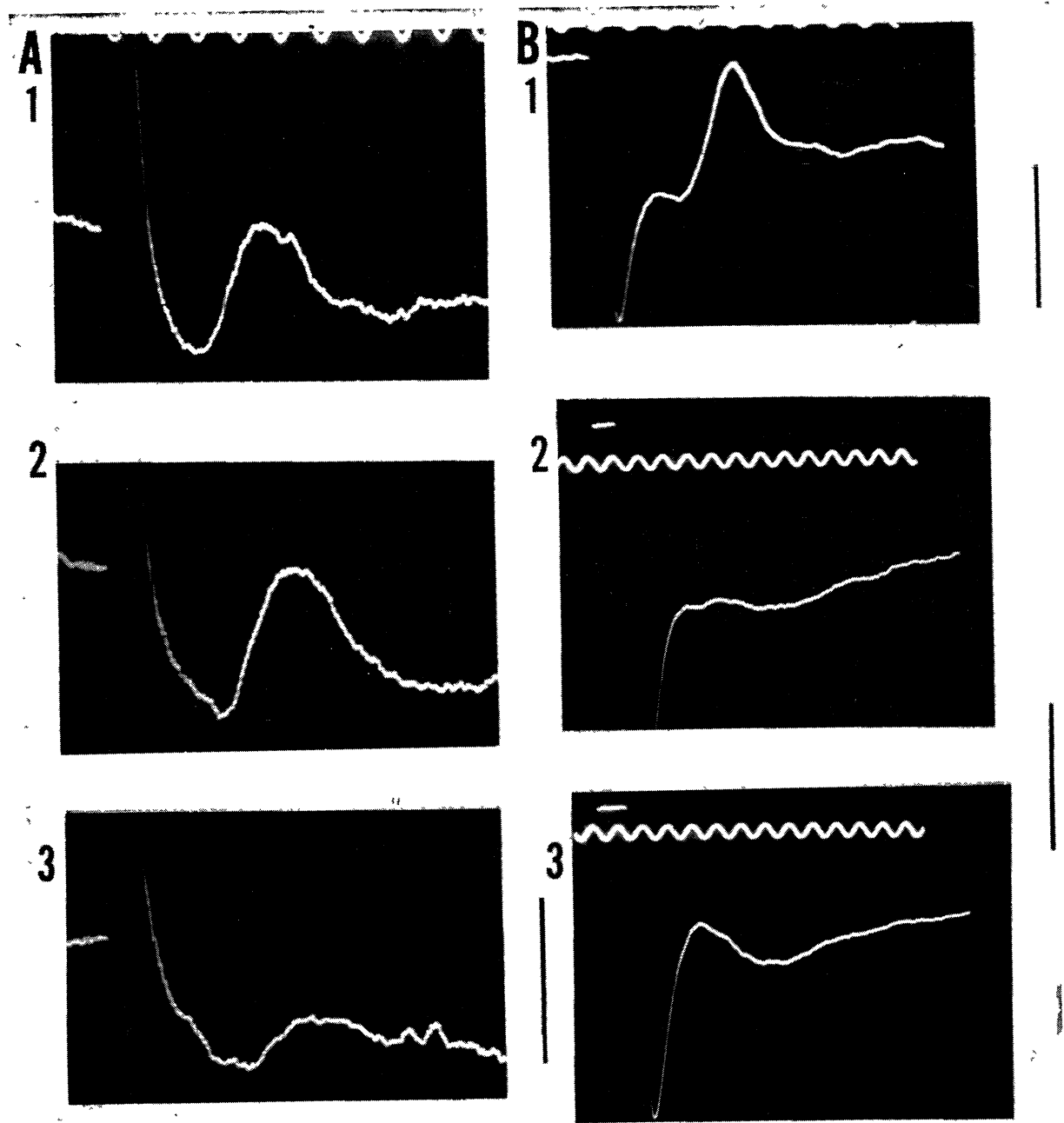

FIG. 3. Changes in the potential with external $\mathrm{K}$ or $\mathrm{Na}$ concentration change. Each A-1 or B-1 represents the control before the exchange of solution. Showing the effect of external $\mathrm{K}$ concentration raised to $56 \mathrm{mM}$ after $30 \mathrm{sec}$ in $\mathrm{A}-2$ and $90 \mathrm{sec}$ in A-3. Showing the effect on deficiency of $\mathrm{Na}$ concentration in Locke solution by replacing it with cholin after $10 \mathrm{~min}$ in $\mathrm{B}-2$. The potential after $5 \mathrm{~min}$ restored to Locke solution indicated in B-3. Time mark: $1 \mathrm{msec}$, vertical bar: $100 \mu \mathrm{v}$ except in $\mathrm{A}-3$, in which is $30 \mu \mathrm{v}$.

polarity of the stimulus was changed. In the partition method, the density of transmembrane current for the nerve fiber is the highest at the both entrances of the hole of the partition wall through which the stalk is laid. Accordingly, the nerve must be stimulated at the cathodic entrance. Therefore, if the polarity of stimulus is changed, the stimulating point is transferred by the wall thickness of $0.67 \mathrm{~mm}$. The results of this method are 
TAble 1 .

The conduction velocity of the first and second waves of the compound action potential.

\begin{tabular}{c|c|c|c|c|c}
\hline \multirow{2}{*}{$\begin{array}{c}\text { No. of } \\
\text { Expt. }\end{array}$} & $\begin{array}{c}\text { Conduction } \\
\text { distance } \\
(\mathrm{mm})\end{array}$ & \multicolumn{2}{|c|}{$\begin{array}{c}\text { Conduction time } \\
(\mathrm{msec})\end{array}$} & \multicolumn{2}{c}{$\begin{array}{c}\text { Conduction velocity } \\
\text { (m/sec) }\end{array}$} \\
\cline { 2 - 5 } & 0.67 & 1 st & 2 nd & 1 st & 2nd \\
\hline 1 & 0.67 & 0.43 & 0.83 & 1.49 & 0.81 \\
3 & 0.65 & 0.35 & 0.93 & 1.56 & 0.72 \\
4 & 0.41 & 0.90 & 1.86 & 0.72 \\
5 & 0.42 & & 0.69 & & 0.60 \\
\hline
\end{tabular}

listed in TABLE 1, No. 1 and 2. The velocity thus obtained was compared with that obtained by the first method. But there was no significant difference between the results. The mean conduction velocity of the first wave was $1.64 \pm 0.26 \mathrm{~m} / \mathrm{sec}$ and that of the second wave was $0.69 \pm 0.17 \mathrm{~m} / \mathrm{sec}$.

II. Oxytocin release evoked by electrical stimulation of the stalk

1) Comparison of the electrical stimulation with the potassium depolarization. When the isolated pituitary gland in the partition box was stimulated for 5 min with repetitive pulses at $20 \mathrm{~Hz}$, each pulses being $2.5-3.0 \mathrm{~mA}$ in intensity and $1 \mathrm{msec}$ in duration, the amount of oxytocin released was $9.1 \pm 2.6$ $\mathrm{mu} / \mathrm{gland}$ on an average of 5 experiments. This is about 10 times higher than the control value of $0.94 \pm 0.13 \mathrm{mu} /$ gland, which means the resting release. Furthermore, this is also twice as high as the value of $5.2 \pm 2.4 \mathrm{mu} / \mathrm{gland}$ which was obtained by exposing the gland to excess $\mathrm{K}^{+}$Locke solution for 5 min. Clearly the repetitive pulse stimulation is more effective than the depolarization by excess $\mathrm{K}^{+}$Locke solution for oxytocin release.

2) The effect of pulse frequency. The gland was stimulated repeatedly for $5 \mathrm{~min}$ at $35 \mathrm{~min}$ intervals with various frequencies, keeping the stimulus intensity always $3.0 \mathrm{~mA}$. Three typical examples are illustrated in Frg. 4, in which the amount of hormone output is plotted against the pulse frequency. The most effective frequency for the release of either oxytocin or vasopressin was $10-20 \mathrm{~Hz}$. The output of the hormone markedly decreased at points higher or lower than this optimal frequency. At less than $5 \mathrm{~Hz}$ almost no secretion was detectable.

3) The effect of pulse intensity. The stalk was stimulated at $20 \mathrm{~Hz}$ for $5 \mathrm{~min}$ with various intensities. The relation between the stimulus intensity and oxytocin release is indicated in FIG. 5. The point located on the ordinate axis expresses the resting value. Although all points in the figure were not 


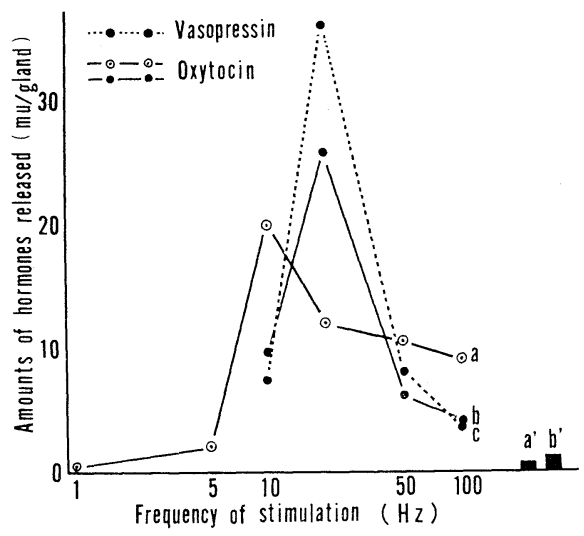

FIG. 4. The relation between the amount of hormone released and the pulse frequency. The curve $a$ and $b$ indicate the output of oxytocin released from the different gland. $a^{\prime}$ and $b^{\prime}$ on the right end represent the output of oxytocin at the resting state (non-stimulus), corresponding to each curve $a$ and $b$. The curve $c$ represents the output of vasopressin. Curve $b$ and $c$ are the data obtained from the same gland.

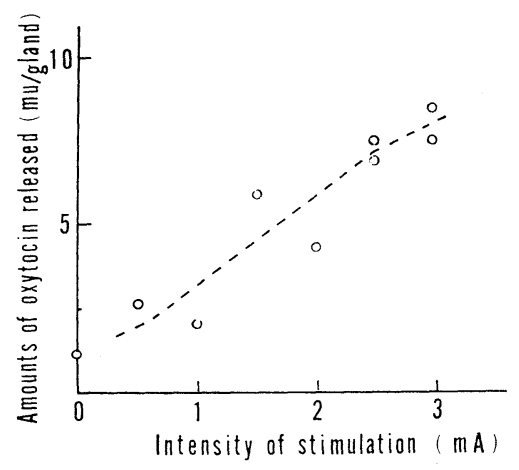

FIG. 5. The relation between the amount of oxytocin released and the intensity of stimulation. Each point represents the output of oxytocin stimulated with $20 \mathrm{~Hz}$ for $5 \mathrm{~min}, 1 \mathrm{msec}$ in duration with various intensities indicated on the abscissa.

data from one and the same gland, it is clear that the amount of secretion increased almost linearly with increasing stimulus intensity.

III. Correspondence of the oxytocin secretion to the action potential at the stalk stimulation

In order to examine the correspondence of the oxytocin release from the terminal to the propagated action potentials through the stalk, the following experiment was carried out. Immediately after the collection of the solution 
for the assay of the control release, about $0.6 \mathrm{ml}$ of Locke solution was put in, and a single shock stimulation was given three times with $30 \mathrm{sec}$ interval to record the control action potential (FIG. 6-1). Then, the repetitive stimulation for $5 \mathrm{~min}$ was given, and the action potentials were recorded at some
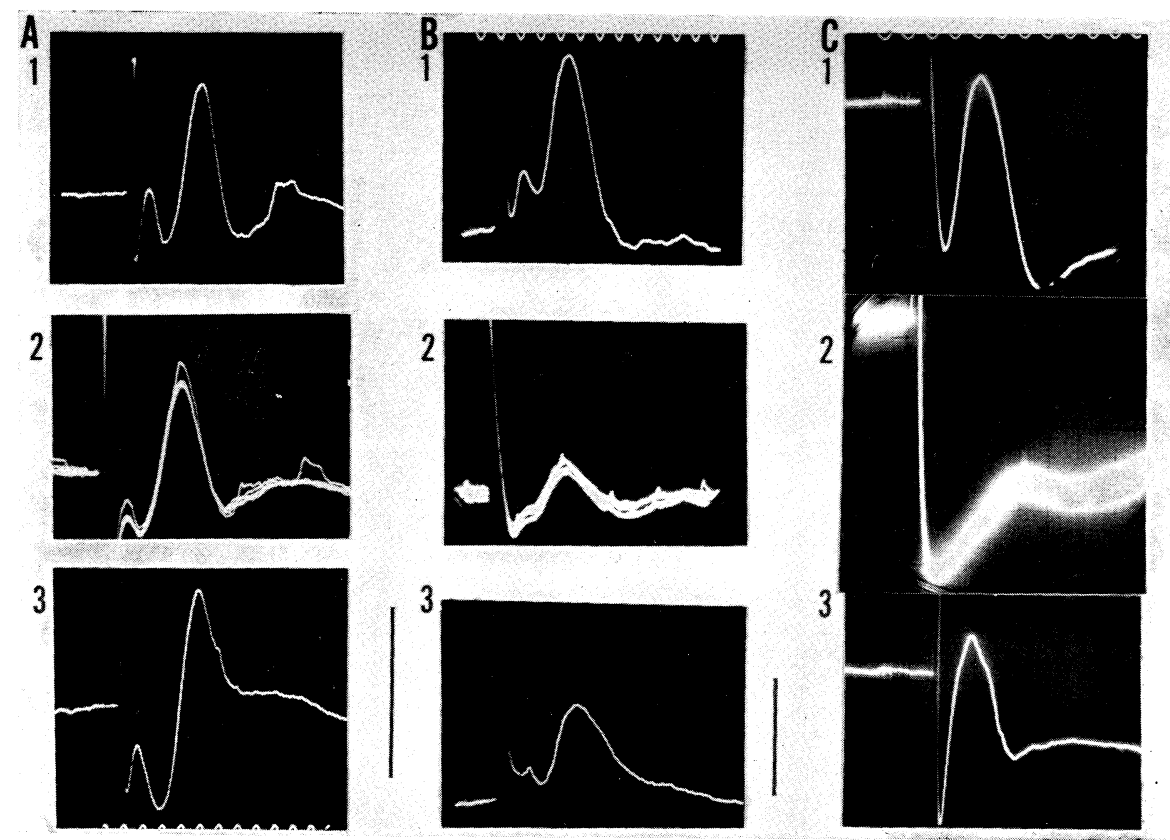

FIG. 6. Changes in compound action potential produced by repetitive pulse stimulation. Stimulating frequency, A: $5 \mathrm{~Hz}, \mathrm{~B}: 10 \mathrm{~Hz}, \mathrm{C}: 20 \mathrm{~Hz}$. 1: control action potential, 2: potentials recorded during 5 min stimulation, A, after $60 \mathrm{sec}$ from the beginning of stimulation, $\mathrm{B}$ and $\mathrm{C}$, after $30 \mathrm{sec}$. 3 : the restored potential recorded $10 \mathrm{~min}$ after stimulation. Time mark : $1 \mathrm{msec}$, vertical bar : $100 \mu \mathrm{v}$.

time during the stimulation. Two minutes after the cessation of stimulation, the solution in the chamber $\mathrm{C}_{1}$ was collected for the measurement of oxytocin content. Ten of the results which indicated a certain bearing of the action potential with the amount of oxytocin released during stimulation were obtained. The amplitude of action potential markedly decreased when it was stimulated with a frequency more than $10 \mathrm{~Hz}$. Three of the results were illustrated in FIG. 6-FIG. 8. The changes and the restorations in the action potential stimulated with the frequency of $5 \mathrm{~Hz}, 10 \mathrm{~Hz}$ and $20 \mathrm{~Hz}$ of repetitive pulse each are indicated in FIG. 6. The time course of the relative size of the second wave was plotted in FIG. 7. In case of the relative size of the wave obtained with $5 \mathrm{~Hz}$ stimulation, its decrease was slight, while the wave obtained with $10 \mathrm{~Hz}$ or $20 \mathrm{~Hz}$ almost disappeared in $1 \mathrm{~min}$. In all cases, however, the definite restorations were seen $10 \mathrm{~min}$ after the cessation of the 


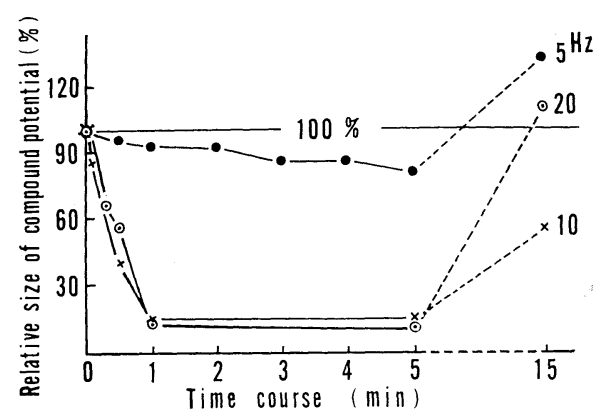

FIG. 7. Decrease in the size of the second wave during repetitive pulse stimulation for $5 \mathrm{~min}$ with three different frequencies. The relative size is expressed in percentage of the control. Points on the right end indicate the recovered size after 10 min rest.

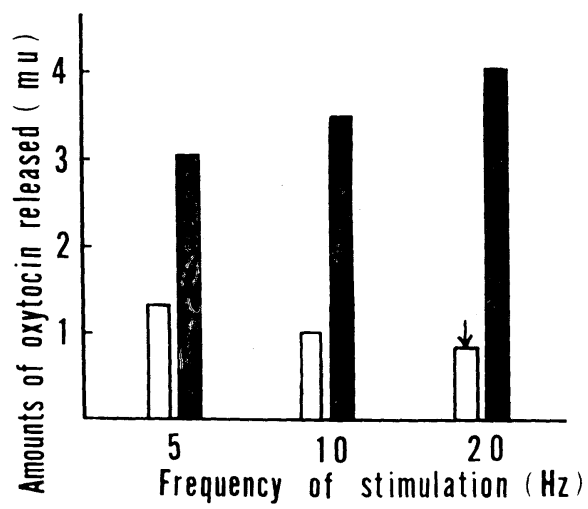

FIG. 8. Amounts of oxytocin released by the repetitive pulse stimulation for 5 min. Each result corresponds to the result of FIGs. 6 and 7 . White column indicate the value of resting gland and black one the value of stimulated one. The resting value with an arrow is possibly overestimated, because of the technical limitation in bioassay.

stimulus (FIG. 6-3). The amounts of oxytocin release stimulated with three different frequencies are illustrated in FIG. 8. The results show that the most effective frequency of stimulation for oxytocin release is $20 \mathrm{~Hz}$ which coincided with the above result (FIG. 4), though the corresponding size of action potential during the stimulation are not large enough (see FIG. 6).

\section{DISCUSSION}

It has been shown by Brooks et al. (1966) that the electrical stimulation at the pituitary stalk in postpartum cat in situ raises the milk ejection pressure, but it has not yet been proved whether or not the electrical stimulation 
directly causes the oxytocin release from the terminal of the nerve fiber passing through the stalk. Meanwhile, HALLER et al. (1965) and MikiteN (1967) studied whether or not the electrical field stimulation can produce the vasopressin release on the isolated neurohypophysis of the rat, but the electrical activity of the nerve fiber or its terminal was not observed simultaneously. In the present experiment, both the recording of the compound action potential and the measurement of oxytocin output produced by the same electrical stimulation were carried out with one and the same preparation. The partition box was quite useful for this purpose. In the present study, the oxytocin release from the gland stimulated at $20 \mathrm{~Hz}$ was several to 10 times higher than that from the non-stimulated one. It was pointed out by Mikiten (1967) that the optimal frequency for the vasopressin release was also about $20 \mathrm{~Hz}$ on the field stimulation. And the stimuli of lower or higher frequencies than $20 \mathrm{~Hz}$ were less effective on the hormone release.

\section{Characteristics of compound action potential}

There have been a few reports on the action potential of the neurosecretory neuron. The characteristic pattern of the action potential of neurosecretory nerve in lower vertebrate was shown by previous authors (BENNETT and FOX, 1962; BERN and YAGI, 1964). The conduction velocity of nerve fibers in hypothalamo-hypophysial tract of the cat (IsHIKAWA et al., 1966) or the rat (YAGI et al., 1966) were in the range between 0.6 to $1.4 \mathrm{~m} / \mathrm{sec}$. The present results also coincided with those. These figures would be also reasonable with reference to PALAY's electron microscopic study of the non-myelinated nerve fibers in the neural lobe.

It is worth to mention here that at least two groups of nerve fibers which have different conduction velocities are contained in the neurohypophysis. Unfortunately, the functional difference between the two has not yet been clarified. However, it was pointed out by DANDY (1913) that the majority of fibers in the neurohypophysis of the dog and the cat were secretory fibers, while some of them were vasomotor fibers. There is an example of the action potential being related to the failure of oxytocin secretion. In this case, the first wave had already disappeared before the repetitive stimulation and only the second wave was seen. This second wave remained as large as $30 \%$ after the $5 \mathrm{~min}$ stimulation with $20 \mathrm{~Hz}$, however, no output of oxytocin was detected. Then, it is suggested that not the second wave, but the first wave of compound action potential is related to the oxytocin secretion.

The relation between the electrical activity and the secretory response

The role of electrical activity on the neurosecretion of hormone has been supposed by many workers, but the problem is still unsolved. According to KATZ (1962), the regulating factor for the transmitter release was the 
presynaptic potential in the neuromuscular junction of the frog. KATZ and MILEDI (1967b) stated that the depolarization of the presynaptic terminal would cause an increase in the permeability to $\mathrm{Ca}^{++}$which, in turn, increased $\mathrm{Ca}^{++}$influx into the cell, and that the real secretory response might be triggered by this $\mathrm{Ca}^{++}$(KATZ and MILEDI, 1965 and 1967a). A similar speculation was introduced by Douglas (1966) on the secretory mechanism of catecholamine from the adrenal medulla and vasopressin from the neurohypophysis. In the adrenal medulla, the direct cause of depolarization of the chromaffin cell is not the propagated impulse but acetylcholine (Ach) released from the secretory nerve terminal (Douglas et al., 1967). But it was confirmed that the neurohypophysial hormone could not be released by Ach applied to the isolated pituitary gland (Douglas and Poisner, 1964; Dicker, 1966; Daniel and LEDERIS, 1967). Therefore, it is likely that the change in permeability to $\mathrm{Ca}^{++}$at the terminal of neurosecretory fiber in the neurohypophysis is caused by the arrival of the impulse itself. It was shown in an example that the action potential was not conducted until the distal electrode was placed at $2.09 \mathrm{~mm}$ from the stimulating point, although it was clearly seen at the proximal electrode placed at $1.59 \mathrm{~mm}$ from the stimulating point. In this case the amount of oxytocin released was less than twice of the control value, even though it was stimulated strongly enough with frequency of $10 \mathrm{~Hz}$ for $5 \mathrm{~min}$. Therefore, it is certain that only little oxytocin is released when the impulse is not propagated to the nerve terminal.

The size of action potential of the neurohypophysis was decreased by a repetitive pulse, especially at a higher frequency more than $10 \mathrm{~Hz}$, as shown in FIG. 7. This depression is probably due to the sustained depolarization produced by repetitive pulses which suppresses the impulse formation corresponding to the high frequency stimulation, as shown by MASHIMA and WAsHio (1968), in the frog skeletal muscle fiber. Consequently, the size of action potential declined markedly but the depolarization would be sustained at the terminal by the frequent arrival of the action potential, so that the amount of hormone release would rather be augmented. The depolarization at the nerve terminal may be essential for the secretory mechanism and the propagated impulse may effectively cause the depolarization at the terminal. But only a transient depolarization at the terminal caused by a few impulses seemed to have little effect, because the low frequency stimulation at less than $5 \mathrm{~Hz}$ was entirely ineffective on the release of hormone.

\section{SUMMARY}

1. Applying the electrical stimulation on the isolated neurohypophysis of the rat, the oxytocin release was bioassayed and the compound action potential was recorded. 
2. The repetitive pulse stimulation at the optimal frequency (about $20 \mathrm{~Hz}$ ) was more effective on the oxytocin release than the excess $\mathrm{K}^{+}$stimulation to the gland.

3. Two waves were separated in the compound action potential traveling along the stalk evoked by a single shock. The conduction velocity of the first wave was $1.64 \pm 0.26 \mathrm{~m} / \mathrm{sec}$ and that of the second wave was $0.69 \pm 0.17 \mathrm{~m} / \mathrm{sec}$. 4. While a marked decrease in the size of the action potential was observed, the output of oxytocin was not declined by the repetitive stimulation at $10 \mathrm{~Hz}$ or $20 \mathrm{~Hz}$.

5. The relation between the electrical activity and the secretory mechanism was discussed, and it is suggested that the depolarization at the nerve terminal may be directly linked to the secretory activity.

I wish to express my thanks to Professor H. MAshima for reading the manuscript and for many valuable discussions, and thanks are also expressed to Miss K. Murata for helpful assistance in these experiments.

\section{REFERENCES}

1) Bennett, M.V.L. And Fox, S. Electrophysiology of caudal neurosecretory cells in the skate and fluke. Gen. comp. Endocr. 2: 77-96, 1962.

2) BeRn, H.A. AND YAGI, K. Electrophysiology of neurosecretory system. "Proc. of the 2nd Int. Congress on Endocrinology" Excerpta Medica Int. Congress Series 83: 577-583, 1964.

3) Brooks, C. McC. AND Kolzumi, K. Control of the neurons of the supraoptic and paraventricular nuclei. Studies in Physiology, pp. 18-23, Springer-Verlag Berlin, Heiderberg, New York, 1965.

4) Brooks, C. McC., Ishikawa, T., Koizumi, K. And Lu, H-H. Activity of neurons in the paraventricular nucleus of the hypothalamus and its control. J. Physiol. $182: 217-231,1966$.

5) Dandy, W.E. The nerve supply to the pituitary body. The Ame. J. of Anatomy $15: 333-343,1913$.

6) Daniel, A.R. ANd Lederis, K. Release of neurohypophysial hormones in vitro. J. Physiol. 190 : 171-187, 1967.

7) De Robertis, E. Histophysiology of synapse and neurosecretion. pp. 159-182, The Macmillan Comp. New York, 1964.

8) DiCKer, S.E. Release of vasopressin and oxytocin from isolated pituitary glands of adult and new born rats. J. Physiol. 185: 429-444, 1966.

9) Douglas, W.W. And Poisner, A.M. Stimulus-secretion coupling in a neurosecretory organ: The role of calcium in the release of vasopressin from the neurohypophysis. J. Physiol. 172 : 1-18, 1964.

10) Douglas, W.W. Calcium-dependent links in stimulus-secretion coupling in the adrenal medulla and neurohypophysis. From "Mechanism of release of biogenic amines" Proc. of an Int. Wenner-Gren Symposium. pp. 267-290, Pergamon Press, 1966.

11) Douglas, W.W., Kanno, T. And Sampson, S.R. Effect of acetylcholine and other medullary secretagogues and antagonists on the membrane potential of adrenal chromaffin cells: An analysis employing techniques of tissue culture. $J$. 
Physiol. $188:$ 107-120, 1967.

12) Haller, E.W., Sachs, H., Sperelakis, N. and Share, L. Release of vasopressin from isolated guinea pig posterior pituitaries. Amer. J. Physiol. 209: 79-83, 1965.

13) IsHidA, A. The effect of tetrodotoxin on calcium-dependent link in stimulussecretion coupling in neurohypophysis. Jap. J. Physiol. 17:308-320, 1967.

14) IsHidA, A. Stimulus-secretion coupling on the oxytocin release from the isolated posterior pituitary lobe. Jap. J. Physiol. 18: 471-480, 1968.

15) Ishikawa, T., Kolzumi, K. AND Brooks, C. McC. Electrical activity recorded from the pituitary stalk of the cat. Amer. J. Physiol. 210: 427-431, 1966.

16) IWASAKI, S. Electrical activity of the secretory neuron on X-organ of crayfish. Proc. of Int. of Physiol. Science p. 213, 1968.

17) KAndel, E.R. Electrical properties of hypothalamic neuroendocrine cells. J. gen. Physiol. $47:$ 691-717, 1964.

18) KATZ, B. The transmission of impulses from nerve to muscles and subcellular unit of synaptic action. Proc. Roy. Soc. B155: 455-477, 1962.

19) KATz, B. AND Miledi, R. The effect of calcium on acetylcholine release from motor nerve terminals. Proc. Roy. Soc. B161: 496-503, 1965.

20) KATZ, B. AND MILEDI, R. On the timing of calcium action during neuromuscular transmission. J. Physiol. 189 : 535-544, 1967a.

21) Katz, B. ANd Miledi, R. A study of synaptic transmission in the absence of nerve impulses. J. Physiol. 192: 407-436, 1967b.

22) Mashima, H. AND WAshio, H. The changes in membrane potential produced by alternating current or repetitive square pulses in the frog skeletal muscle fibers. Jap. J. Physiol. 18: 403-416, 1968.

23) Mikiten, T.M. and Douglas, W.W. Effect of calcium and other ions on vasopressin release from rat neurohypophysis stimulated electrically in vitro. Nature 207 : No. 4994, p. 302, 1965.

24) Mikiten, T.M. Electrically stimulated release of vasopressin from rat neurohypophysis in vitro. Ph D. Thesis Yeshiva University, New York, 1967.

25) PALAY, S.L. The fine structure of the neurohypophysis. In "Ultrastructure and cellular chemistry of neural tissues" Ed. by WAELSCH, H., p. 31-49 (Progress in Neurobiology, 2: Eds. Korey, S.R. and Nurnberger, J.I.) Hoeber, New York, 1957.

26) Yagi, K., Azuma, T. And Matsuda, K. Neurosecretory cell: Capable of conduction impulse in rats. Science 154 : No. 3750, 778-779, 1966. 